Dhaka Univ. J. Biol. Sci. 23(1): 61-67, 2014 (January)

\title{
THE REPRODUCTIVE BIOLOGY OF FLESH FLY, BOETTCHERISCA PEREGRINA (ROBINEAU-DESVOIDY, 1830) (DIPTERA: SARCOPHAGIDAE)
}

\author{
Md. Zahidur Rahman Majumder, Mohan Kumar Dash ${ }^{1}$, Humayun Reza Khan ${ }^{1}$ \\ AND RAFIA AKHTAR KHAN \\ Radiation Entomology and Acarology Division, Institute of Food and Radiation Biology (IFRB), \\ Atomic Energy Research Establishment (AERE), Ganakbari, Dhaka, Bangladesh
}

Key words: Reproductive biology, Flesh fly, Boettcherisca peregrina

\begin{abstract}
The reproductive biology of the flesh fly, Boettcherisca peregrina (Diptera : Sarcophagidae ) was studied in the blowfly laboratory $\left(25-30^{\circ} \mathrm{C}, 60-80 \% \mathrm{RH}\right.$ and 12 hrs light and 12 hrs dark) of the Institute of Food and Radiation Biology, Atomic Energy Research Establishment, Dhaka. The female reproductive system of $B$. peregrina comprises of two ovaries, two lateral oviducts, a common oviduct, three spermathecae, and a pair of accessory gland, a bilobed incubation pouch, vagina and genital opening. The male reproductive system $B$. peregrina consists of a pair of testes, a pair of vasa deferentia, a pair of accessory gland, a median ejaculatory duct, an ejaculatory sac and aedeagus. There is a general trend of gradual development of different organelles of the male and female reproductive systems from adult emergence to reproductive maturity. Protein diet was essential for proper development of female reproductive system. Oocyte development was apparent in both protein fed and protein unfed females. The mean sex-ratio of male to female was 20.2 : 14.2.
\end{abstract}

\section{Introduction}

The flesh fly, Boettcherisca peregrina (Robineau-Desvoidy, 1830) (Diptera: Sarcophagidae) is an important ectoparasite as it causes myiasis in human and other mammals. It has become a great concern in Bangladesh as it is a serious agent affecting human health, livestock, fish and other animal food processing factories. The maggots of this species take their nourishment from unprotected fish and meat, contaminate them and reduce their nutritional value. Particularly, B. peregrina causes a significant loss to fish drying industries of the coastal and off-shore islands in the Bay of Bengal. Majumder et al.(1) studied the biology of B. peregrina in the laboratory.

The institute of Food and Radiation Biology, Atomic Energy Research Establishment, Saver, Dhaka has been conducting a research on three Sarcophagid major pests including B. peregrina using sterile insect technique (SIT) in the off-shore island of Bangladesh. For

${ }^{1}$ Department of Zoology, University of Dhaka, Dhaka-1000, Bangladesh. 
the research on SIT, the information on reproductive and behavior of biology of the pest is essential. Therefore, in the present research the reproductive and behavioral biology of B. peregrina was conducted in the laboratory.

\section{Materials and Methods}

The reproductive biology of $B$. peregrina, was studied in the blowfly laboratory of Radiation Entomology and Acarology Division, Institute of Food and Radiation Biology (IFRB), Atomic Energy Research Establishment (AERE), Savar, Dhaka from April, 2010 to March, 2011.

The adult flies collected from the stock culture of the laboratory were dissected under a stereoscopic binocular microscope (Nikon) to observe the structure of the reproductive system. The pertinent organs of the reproductive system were cleaned up and preserved in $70 \%$ ethyl alcohol. The different components of reproductive system were photographed by using a Nikon binocular microscope.

In one experiment, the effects of food on the female reproductive system of $B$. peregrina were studied. Fifty virgin adult females were reared throught life with bovine liver, sugar and water in one cage $(30.48 \times 20.32 \times 20.32 \mathrm{~cm})$ treatment. In another cages 50 virgin females from the same stock culture only in another cage of the same size.

In another experiment, two cages each with 50 males and females at a ratio $1: 1$ were determined the effects of mating on the reproductive system of B. peregrina. These flies were supplied with bovine liver, sugar and water. Two other cages were similarly arranged as above except that the flies were provided with sugar and water as their food. The mated flies of the two tests were isolated in separate cages $(20.32 \times$ $15.24 \times 15.24 \mathrm{~cm}$ ) to above the fecundity of the females.

The records were kept on the number of eggs laid by a single female and the percentages of maggots laid. Mosts of the time, the females gave birth to 1st instar larva. The total number and undeveloped larva were counted within $24 \mathrm{hrs}$.

Thirty five eggs were placed in different larval rearing bowls for pupation and emergence of the adults. The total number of the adults emerged were recorded. The sexes of the adults emerged were determined under a microscopic observation.

\section{Results and Discussion}

The soft, shiny female reproductive system of $B$. peregrina was closely attached to the ventral surface of the abdominal wall (Fig. 1). The protein diet showed significant influence on the development of different organelles of the fermale reproductive system. The different organelles are described below.

The female contained a pair of ovary. Each ovary is composed of a group of polytrophic ovarioles. The ovaries attained maturity after the flies were provided with 
fresh blood meal of bovine liver. There was a little development of the ovaries as found in the protein unfed females, but these females did not lay eggs.

The number of oocytes that a female can rear up depends on her size and the amount of protein rich material ingested ${ }^{(2-3)}$. Water, carbohydrate and protein influence the ovarian development of L. cuprina(4). Browne(5) also predicted that the female L. cuprina required protein for attaining the maturity of oocytes. The present study showed almost similar development of oocytes in the ovaries of both types of females feeding on bovine liver, sugar and water, and those feeding on sugar and water only. This result suggests that B. peregrina is less adapted than L. cuprina in oocyte development on protein deficient food.

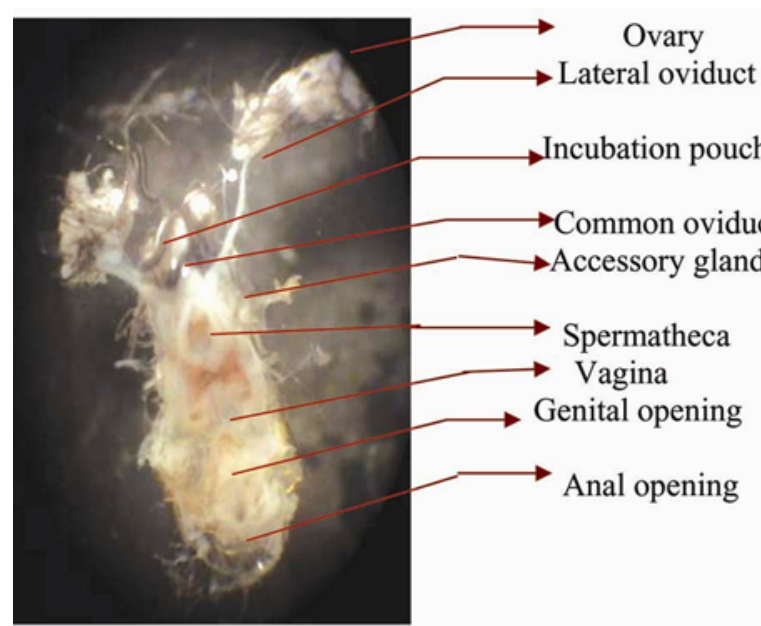

Dorsal view

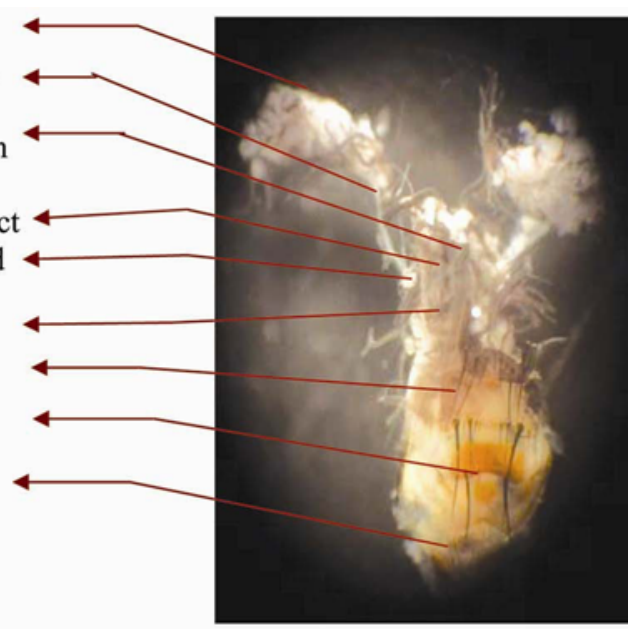

Ventral view

Fig. 1. Dorsal and ventral views of female reproductive system of the newly emerged adult of B. peregrina depicting various organelles. (Magnification $=2 x$ ).

A pair of transparent white lateral oviduct led posteriorly from the ovaries. In newly emerged adult, the ducts were narrow and long which gradually became shortened and broadened during the process of egg maturation and attained maximum size during oviposition period.

The paired lateral oviducts were fused at distal end to form a common oviduct which is distally connected to the bilobed incubatory pouch. The common oviduct also showed gradual increase in size which attained maximum size during oviposition period. The length and breadth of common oviduct were relatively smaller when the eggs remained in the egg pouch.

The paired accessory glands were tubular in shape with globular terminal end, whitish, and two in number and originated from the dorso lateral side at the base of the vagina. Keilin ${ }^{(6)}$ reported a pair of tubular accessory gland opening into the dorsal region 
of the vagina in Anopheles and Similium. The gland was larger in tabanids, elongated and filiform in Musca, Hypoderma and most other Calyptratae. These glands usually secrete a viscid substance which enables the eggs to adhere to one another or to the substratum, and also it secretes a milky fluid, which serves to nourish the intra-larva of Glossina and Pupipar(6). The present study reveals the occurrence of a pair of long, tubular accessory glands filled with whitish substances in different developmental phases.

The three spermathecae were tubular with brown sclerotised head, remained connected to respective lateral oviduct and rest one to common oviduct. The size of spermatheca was relatively larger during the oviposition phase which was relatively small in the next post-oviposition phase. Kelin(6) reported two dark brown or black globular spermathecae in Mansonia, Plebotomus and Dacus species.

The bilobed whitish incubatory pouch was squeezed in early stage with many tracheae. The developed eggs in the ovary pass through the lateral and common oviduct prior to entering the incubatory pouch which remained connected to the common oviduct and made the pouch expanded which became squeezed again during the postoviposition phase. The present investigation supports the findings of Sanborne ${ }^{(7)}$. Superiority in the reproductive system of B. peregrina is also apparent from completion of embryonic development of the incubatory pouch of the female reproductive system. The necessary supply of oxygen in the incubation pouch of female reproductive system for embryonic/1st instar larval development might be ensured through apparently rich tracheal supply over incubation pouch.

The vagina was the leading expanded muscular tube. There was a brown color sclerotic structure on the dorsal wall of vagina. The organ attained its highest maturity during the oviposition phase. The genital opening was situated ventrally on the $9^{\text {th }}$ abdominal segment of the female B. peregrina.

The adult male possessed a pair of elongated cone shaped and brown colored testes one on each side of the abdomen laying just below the alimentary canal which attained deep brown color and devoid of fat body (Fig. 2).

The vasa deferentia were whitish paired canal originating one from the broader end of testis and were longer in the late stages.

The ejaculatory duct was a simple, long, narrow tube which led to the ejaculatory sac formed by the union of two vasa deferentia. The tubular ejaculatory duct was light to deep creamy in color and usually remained coil state. The proximal part of the duct was much greater in size than the distal part. The testes were cylindrical in shape and yellowish brown in color, vasa deferentia was relatively short and ejaculatory duct was long as described by Keuchenius( ${ }^{(8)}$ in Culex mosquitoes. The vasa deferentia were generally short and became confluent distally to form a common ejaculatory duct.

One pair of soft, tubular, whitish and twisted accessory glands was originated from the anterior end of the ejaculatory duct just behind the union of vas deferens. 
Eshcherich ${ }^{(9)}$ reported one to three pairs of tubular or sac-like mesadenia and ectadenia type accessory glands in the male genital system of Musca and Tabanus. Keuchenius( ${ }^{(8)}$ reported that in Culex each vas deferens is enlarged distally to form a vesicular seminalis and two pyriform accessory glands open into a very short ejaculatory duct. In the present study the accessory glands are almost similar to that in Musca and Tabanus.

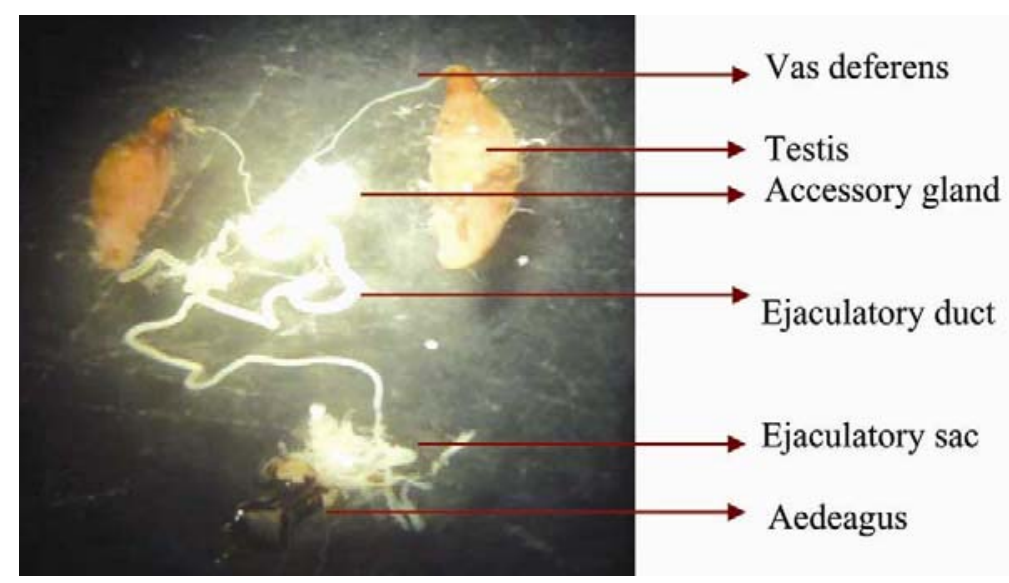

Fig. 2. Male reproductive system of adult B. peregrina. (Magnification $=2 x$ ).

The basal portion of the ejaculatory duct of $B$. peregina possessed a muscular sac-like structure known as ejaculatory sac, situated just before the aedeagus. Hewit ${ }^{(10)}$ reported a sclerotized, filiform ejaculatory sac in Musca. Keuchenius( ${ }^{(8)}$ also confirmed the occurance of ejaculatory sac in many Diptera. Present investigation shows the occurrence of a small muscular sac-like ejaculatory sac in B. peregrina, situated behind the male genitalia.

The terminal part of the ejaculatory duct was enclosed in a finger-like evagination of ventral body wall which forms the male aedeagus. Stoffolano et al.(11) stated that the size of adeagus of male Phormia regina in the wild flies showed position correlation to their body size. The adeagus of $B$. peregrina was also similar to the adeagus of the blowfly Phormia regina(11).

The male to female sex ratio of $B$. peregrina was recorded as $3: 2$. Protein diet was not essential for the mating behavior of B. peregrina. Kamal(12) observed that all calliphorids required protein meal prior to copulation which was not necessarily required for $B$. peregrina. Etienne ${ }^{(13)}$ reported that in Ducus cucurbitae, mating took place 5 to 7 days after emergence and oviposition began on the following day. Browne et al. (14) observed that the most females of L. cuprina mated soon after their ovarian development. Present observation revealed that mating of $B$. peregrina started after two days of adult emergence when the supply of blood of bovine liver was ensured and each sequence of mating 
continued from 3 to 20 minutes. Similar findings were recorded by Smith et al. ${ }^{(15)}$ who observed that copulation in L. cuprina lasted for around 11 minutes.

The sterile insect technique (SIT), also known as sterile male technique, in which sterile males have potentiality to transmit sterility to the fertile wild female through the process of sexual mating. The sterile male technique involves mass rearing of the pest irradiating them late in the pupal stage with gamma rays and releasing the adults usually from aircraft to compete with wild males in nature. The wild females mated with released males oviposit normally and the embryos initiate development, but die before hatching. The present study on the general biology of B. peregrina will be of great value towards the development of suitable control measures including sterile insect technique either singly or as an important component of intregated pest control methods (IPM).

\section{References}

1. Majumder MZR, MK Dash, RA Khan and HR Khan 2012. The biology of flesh fly, Boettcherisca peregrina (Robineau - Desvoidy, 1830) (Diptera : Sarcophagidae). Bangladesh J. Zool. 40(2): 189-196.

2. Vogt WG, TL Woodburn and ACM Van Gerwin 1985. The influence of oocyte resorption on ovarian development rates in the Australian sheep blowfly, Lucilia cuprina. J. Entomol. Exp. et. App. 39(1): 85-90.

3. Vogt WG, TL Woodburn, BA Elleni, ACM Van Grewin, LB Browne and KG Warohaugh 1985. The relationship between fecundity and oocyte resorption in field populations of Lucilia cuprina. J. Entomol. Exp. et. App. 39(1): 91-99.

4. Clift AD and FJD Mcdonald 1979. Some relationships between diet and ovarian development in Lucilia cuprina (Wied.) (Diptera:Calliphoridae). Aust. J. Zool. 24(1): 87-93.

5. Browne LB 1979. The behavior and nutritional requirements of adults of Lucilia cuprina possibilities for modification. In: National Symposium of the Sheep Blowfly and Flystrike in Sheep. N. S. W, Dept. Ag. Sydney, Australia. pp. 33-43.

6. Keilin D 1916. Sur la viviparite chez les Dipteres et les larves de Dipteres vivipares. Arch Zool. gen. et. Exp. 55: 393-415

7. Sanborne T 1982.Sarcophagous flies in Seuz Province, Egypt. I-seasonal distribution and sexratio. J. Egypt. Soc. Parasitol. 52(5): 582-895.

8. Keuchenius PE 1913. The structure of the internal genitalia of sonic male Diptera. Z. Wiss. Zool. 105: 501-536.

9. Eshcherich K 1894. Anatomische Studien uber das mannlche Genital system der Coleopteran. Z.Wiss. Zool. 57: 620-641.

10. Hewitt CG 1912. Fannia (Homalomyia) canicularis. Linn. and F scalaris Fab. Paraisitol. 5:161-174.

11. Stoffoland JG, EY Gonzalez, NI Sanchez, J Kane, K Velazquez, AL Oqlendo, G Sakolsky, P Scilafer and CM Yin 2000. Relationship between size and mating success in the blowfly Phormia regina (Diptera: Calliphoridae). Ann. Entomol. Soc. Am. 93(3): 673-677.

12. Kamal AS 1958. Comparative study of thirteen species of Sarcosaprophagous Calliphoridae and Sarcophagidae (Diptera) Bionomics. Ann. Ent. Soc. Am. 51:261-271. 
13. Etienne J 1969. Lutte control les mouches des fruits (control of fruit flies). Rapp. Inst. Rech. Agron. trop. Remion. pp. 251-259.

14. Browne LB, ACM Van Gerwin and PH Smith 1987. Relationship between mated status of females and their stage of ovarian development in field population of the Australian sheep blowfly, Lucilia cuprina (Wiedemann) (Calliphoridae: Diptera). Bull. Entomol. Res. 77(4): 609-615.

15. Smith PH, LB Brown and ACM Van Grewin 1988. Sperm storage, utilization and egg fertility in the sheep blowfly, Lucilia cuprina (Wiede.). J. Insect Physiol. 34:125-129.

(Manuscript received on 9 June, 2013; revised on 30 June, 2013) 